\title{
Comparison of mechanical properties of geopolymers from different raw materials with the addition of waste glass
}

\author{
Michal MARCIN ${ }^{1 *}$, Karel DVOŘÁK ${ }^{2}$, Ladislav PAŠEK ${ }^{3}$, Igor D̆URIŠKA ${ }^{4}$,

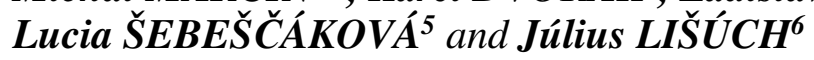

\begin{abstract}
Authors' affiliations and addresses:
${ }_{1,5}$ Technical University of Košice, Faculty of Mining, Ecology, Process Control, and Geotechnologies, Institute of earth resources, Park Komenského 19, 042 00, Košice, Slovak Republic

e-mail: michal.marcin@tuke.sk ${ }^{1}$

${ }^{2}$ Brno University of Technolgy, Faculty of Civil Engineering, Institute of Technology of Building Materials and Components, Veveří 512/95, Brno 602 00, Czech Republic

e-mail: dvorak.k@fce.vutbr.cz

${ }^{3}$ DIAMO state enterprise, Directorate of state enterprise, Department of Mining, Máchova 201, 47127 Stráž pod Ralskem, Czech Republic

email: pasek@diamo.cz

${ }^{4}$ Technical University of Košice, Faculty of Mining, Ecology, Process Control, and Geotechnologies, Institute of Geosciences, Park Komenského 15, 042 00, Košice, Slovak Republic

e-mail: igor.duriska@tuke.sk

${ }^{6}$ Technical University of Košice, Faculty of Mining, Ecology, Process Control, and Geotechnologies, Project Department, Letná 9, 042 00, Košice, Slovak Republic

e-mail: julius.lisuch@tuke.sk

\section{*Correspondence:}

Michal Marcin, The Technical University of Košice, Faculty of Mining, Ecology, Process Control, and Geotechnologies, Institute of earth resources, Department of mineral processing, Park Komenského 19, 042 00, Košice, Slovak Republic

e-mail: michal.marcin@tuke.sk
\end{abstract}

\section{Acknowledgment:}

This research was funded by the European Institute of Innovation and Technology (EIT), a body of the European Union, under the Horizon 2020, the EU Framework Programme for Research and Innovation (Project BioLeach: Innovative Biotreatment of RM, grant number: 18259).

How to cite this article:

Marcin, M., Dvořák, K., Pašek, L., Ďuriška, I.

Šebeščáková, L. and Lišúch, J. (2021).

Comparison of mechanical properties of geopolymers from different raw materials with the addition of waste glass. Acta Montanistica Slovaca. Volume 26 (2) 252-261

DOI:

https://doi.org/10.46544/AMS.v26i2.06

\begin{abstract}
The combustion of fossil fuels results in creating a lot of solid wastes such as fly ash and slag. However, these environmentally unfriendly materials can be used as a raw material for alkali activation geopolymerization. Although these wastes have been successfully used in industrial production for several decades, its use does not achieve the level of its potential. Today, to achieve a sustainable construction industry, alternative cement has been extensively investigated. Geopolymer (GP) is a kind of material that is obtained from the alkaline activator, and it can be produced from industrial wastes or by-products. The aim of this work was to describe the improvement of mechanical properties of alkali-activated binders geopolymers made of fly ash and blast furnace slag. The effect of the addition of waste glass in three different values feed into fly ash or GGBFS, and its impact on mechanical properties (compressive and flexural strengths) of geopolymers was examined. The highest value of compressive strength was achieved with $20 \%$ waste glass addition to a fly ash sample on $90^{\text {th }}$ day $58,9 \mathrm{MPa}$. The waste glass was added in the form of broken and crushed glass particles.
\end{abstract}

\section{Keywords}

Geopolymer, Fly ash, Slag, Compressive strengths, Flexural strengths 


\section{Introduction}

At present, most of the worldwide production of energy is made in heating plants by using combustion of fossil fuels, most of its coal. This process produces a substantial part of solid and gaseous wastes. These products include fly ash, slag, and gypsum (Giergiczny, 2019).

Fly ash (FA), which may contain substances hazardous to the environment, is generated in the process of hard coal and lignite incineration. The present utilization of fly ashes on a worldwide basis varies widely from a minimum of $3 \%$ to a maximum of $57 \%$ of the total produced, with an average of $16 \%$ (Dindi et al., 2019; Wang et al., 2014; Michalíková et al., 2010).

The ground granulated blast-furnace slag (GGBFS) is a by-product of the steel industry by adding limestone to ore to remove non-ferrous contaminants, and it consists of four major chemical components: $\mathrm{CaO}, \mathrm{SiO}_{2}, \mathrm{Al}_{2} \mathrm{O}_{3}$, and $\mathrm{MgO}$ (Snellings et al., 2012). As one of the main by-products during the process of iron and steel making, blast furnace slag is discharged at a super-high temperature of $1450-1650{ }^{\circ} \mathrm{C}$ (Wang et al., 2017).

Fly ash and slag can be used as alkali-activated materials and utilized in the synthesis of geopolymers (GP). The term geopolymer was first used by Joseph Davidovits. He defined the material that is formed in inorganic

polycondensation called geopolymerization. In geopolymerization reaction, three-dimensional structures of $\mathrm{AlO}_{4}$ and $\mathrm{SiO}_{4}$ tetrahedra are created. Later the term geopolymer was used for all alkali-activated aluminosilicate (Arai et al., 2017; Davidovits, 2017; Škvarla et al., 2011; Kanuchova et al., 2016; Sisol et al., 2014).

Geopolymers are generally understood as alkali-activated aluminosilicates. They may be considered an inorganic two-component system consisting of a reactive solid source of $\mathrm{SiO} 2$ and $\mathrm{Al} 2 \mathrm{O} 3$ and an alkaline activation solution (Buchwald et al., 2011). Geopolymers are a new group of inorganic substances because they have important energy and environmental potential. They belong to a group of inorganic polymer covalently bound macromolecules with the chain consisting of -Si-O-Al-O- (Škvára, 2007; Xu \& Van Deventer, 2000).

By tailoring geopolymer mix design and appropriate curing conditions, geopolymers can exhibit extraordinary properties, such as high mechanical strength, high adhesive strength, high fire-resistance, high resistance to the chemical reagent, and low concentrations of leachable heavy or toxic metals, etc. (Wu et al., 2018; Cilla et al., 2014).

Geopolymers are environmentally friendly and sustainable materials that offer viable solutions for global environmental protection, energy conservation, wastewater treatment, solid waste management, and super high performance of geopolymer concrete (Wu et al., 2019; Sisol et al., 2010).

Many studies have examined the possibility of using wastes with different compositions to be mixed with fly ash or slag as raw materials in recent years. The choice of the materials to produce geopolymers depends on parameters such as availability, disposal urgency, the difficulty for recycling, and applications (Toniolo \& Boccaccini, 2017).

The aim of this paper is to compare two different types of geopolymers. One is made from fly ash and the second from GGBFS, with the addition of waste glass (WG), focusing on improving their mechanical properties. Exploring the effects of WG size on mechanical properties was part of our investigation. The objective of the paper was also to study the possibilities of using WG to partly replace FA in the mixture during the process of geopolymer production.

\section{Material and Methods}

The materials used for the alkali activation were fly ash (FA) derived from the combustion of black coal in pulverized coal boilers obtained from an upper layer of the coal-ash sludge bed and blast furnace slag after mechanical activation in a ball mill (GGBFS).

The grinding stage was completed in a two chambers laboratory ball mill with steel balls with different diameters. The laboratory mill used for mechanical activation had a volume of $30 \mathrm{dm}^{3}$ and was filled with a steel ball with diameters ranging from 2 to $10 \mathrm{~cm}$. Material for mechanical activation with steel balls formed $40 \%$ of the mill volume. Revolution was adjusted to 90 per minute. After the grinding time of 60 minutes, the $d_{80}$ value of the material (FA and GGBFS) was $120 \mu \mathrm{m}$. Before alkali activation was material homogenized (FA and GGBFS separately), and there was no need for other treatment of the material. Chemical analysis of materials is in table 1. SEM micrographs of fly ash and GGBFS after the grinding stage are shown in figure 1.

The activation solution was prepared by mixing solid $\mathrm{NaOH}$ pellets with $\mathrm{Na}$-water glass and water. Sodium water glass from the Kittfort Co., Prague, Czech Republic, with a density of $1.328-1.378 \mathrm{~g} / \mathrm{cm}^{3}$ was used. It contains $36-38 \% \mathrm{Na}_{2} \mathrm{SiO}_{3}$, and the molar ratio of $\mathrm{SiO}_{2} / \mathrm{Na}_{2} \mathrm{O}$ is 3.2 - 3.5. Solid $\mathrm{NaOH}$ with a density of 2.13 $\mathrm{g} / \mathrm{cm}^{3}$ was obtained from Kittfort Co., Prague, Czech Republic, containing at least $97 \%-99.5 \%$ of $\mathrm{NaOH}$.

The slag mixture samples with different amounts of waste glass (WG) were prepared. Samples with $10 \%$, $20 \%$, and $30 \%$ by weight and also a reference sample which was created only from GGBFS were prepared. Two different particle sizes of waste glass were used. In the first set of experiments, the particle size of WG was under $1 \mathrm{~mm}$. In the second set, it was over $1 \mathrm{~mm}$. 
GGBFS was first mixed with WG, and after their homogenization, an activation solution was added. The value of the $\mathrm{Ms}$ modulus $\left(\mathrm{SiO}_{2} / \mathrm{Na}_{2} \mathrm{O}\right.$ molar ratio) in the activation solution was adjusted to 1.3. The overall concentration of the alkaline activation agent was adjusted to $7 \% \mathrm{Na}_{2} \mathrm{O}$ in the binder mass. The water-to-fly ash ratio was adjusted to 0.23 . GGBFS and WG mixture was stirred with activation solution for 10 minutes until the creation of a homogenous mixture. The mixture was then filled into prismatic molds with the dimensions $40 \times 40 \times 160 \mathrm{~mm}$ and compacted on the vibration table VSB-40. The pastes were cured in a hot air drying chamber at $80^{\circ} \mathrm{C}$ for 6 hours. Thereafter, the samples were removed from the forms, marked, and stored in laboratory conditions till the moment of the strength test. The values of compressive strength were determined after 7, 28, and 90 days of hardening according to the Slovak Standard STN EN 12390-3. A part of the samples was kept for 28 days at laboratory temperature, then a water absorption test according to the Slovak Standard STN 731316 was performed.

The FA and GGBFS mixture samples with different amounts of waste glass (WG) were prepared. Samples with $10 \%, 20 \%$, and $30 \%$ by weight and a reference sample which was created only from FA and GGBFS were prepared.

Table 1. Chemical composition of materials.

\begin{tabular}{|c|c|c|c|c|c|c|}
\hline Material & $\mathbf{S i O}_{2}$ & $\mathbf{C a O}$ & $\mathbf{M g O}$ & $\mathbf{A l}_{2} \mathbf{O}_{3}$ & $\mathbf{F e}_{2} \mathrm{O}_{3}$ & Other \\
\hline GGBFS [\%] & 40.3 & 37.01 & 12.1 & 8.51 & 0.3 & 1.78 \\
\hline FA [\%] & 32.1 & 1.75 & 0.23 & 14.55 & 7.55 & 24.8 \\
\hline
\end{tabular}

Used WG was an ordinary white bottle glass. WG was collected, washed, and labels were removed to be cleaned completely. WG was broken into pieces with a hammer, and then to unify the particle size was sieved under $1 \mathrm{~mm}$.
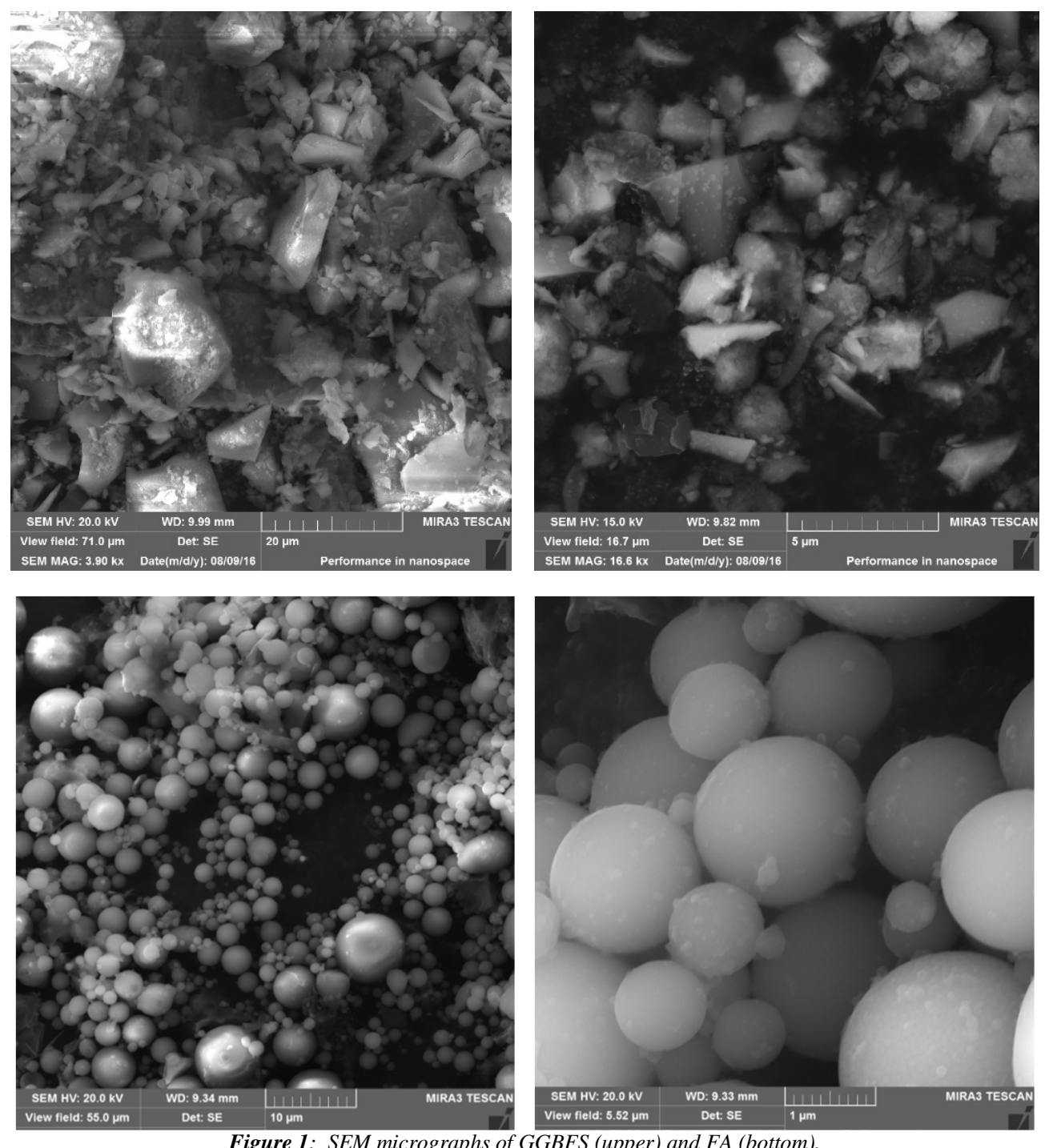

Figure 1: SEM micrographs of GGBFS (upper) and FA (bottom). 


\section{Results and Discussion}

Properties and composition of raw material play an important role in alkali activation. Samples were synthesized from FA and GGBFS with the addition of WG by several proportions. The whole experiment was done in two steps. The first set was with the addition of WG with a size under $1 \mathrm{~mm}$, and the second set was done with WG addition with a size over $1 \mathrm{~mm}$. The effect of $\mathrm{WG}$ addition on final compressive strength and flexural strength was examined.

\section{Addition of WG fraction $<1 \mathrm{~mm}$}

The resulting flexural strengths are shown in Figures 2 and 3 for samples from GGBFS and FA.

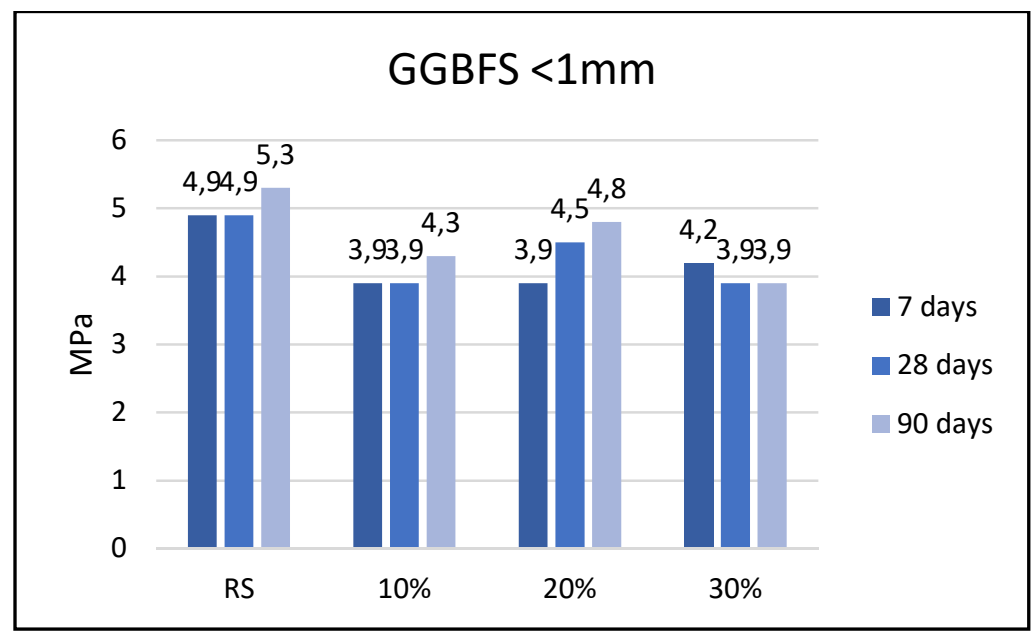

Figure 2. Flexural strength of GP based on GGBFS with the addition of WG below $1 \mathrm{~mm}$

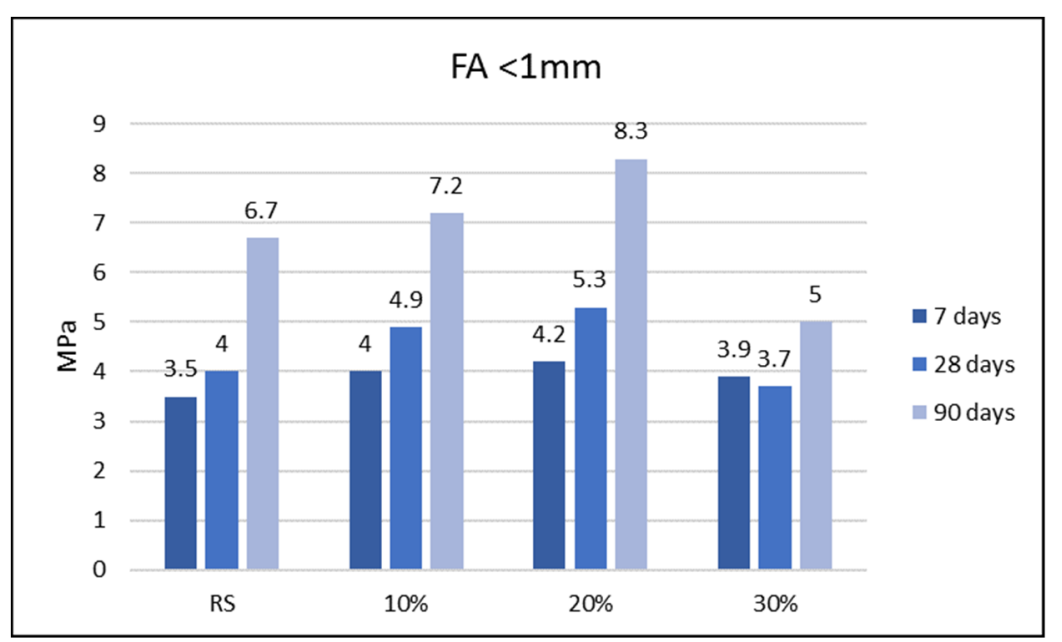

Figure 3. Flexural strength of GP based on FA with the addition of WG below $1 \mathrm{~mm}$.

Flexural strength results show that the maximum strength of almost all samples is achieved on the $90^{\text {th }}$ day (except for the sample GGBFS $30 \%$, maximum was on the $7^{\text {th }}$ day). Regarding geopolymers made from GGBFS, WG addition was unsuccessful because the reference sample achieved higher flexural strengths. Measured strengths were relatively similar on all testing days.

FA based geopolymers, after testing, show diametrically different results. Adding WG to a geopolymer mixture increase flexural strengths.

The highest strength $(8.3 \mathrm{MPa})$ was achieved for the sample with $20 \%$ WG addition at the age of 90 days. The increasing amount of WG in the mixture also increased flexural strengths, but only to the amount of $20 \%$ WG. Higher addition resulted in decreasing strengths in comparison to a reference sample. 


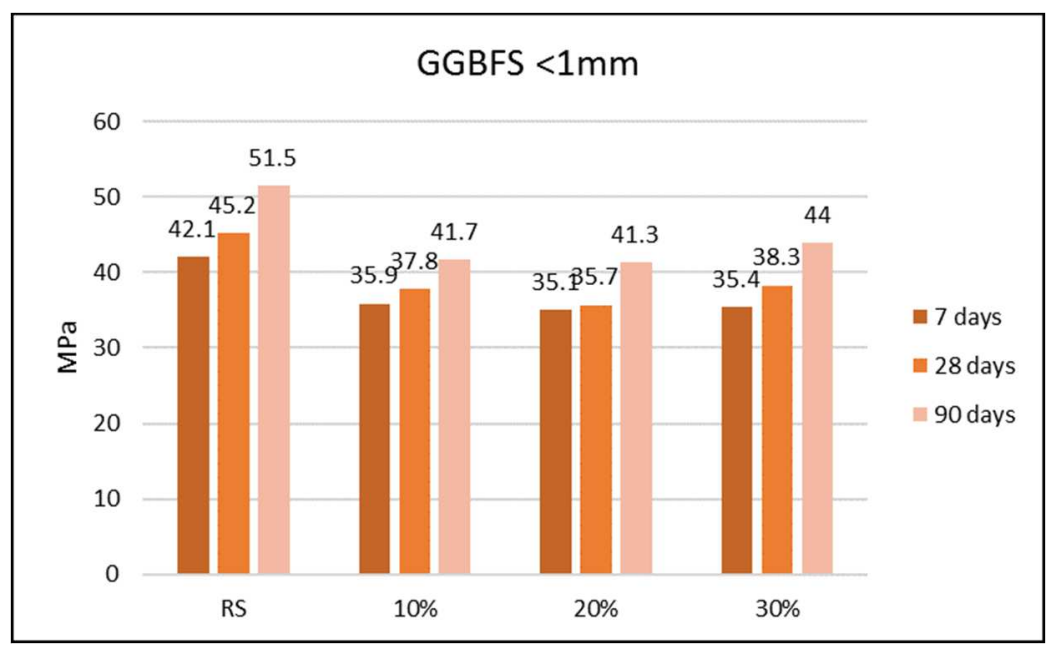

Figure 4. Compressive strength of GP based on GGBFS with the addition of WG below $1 \mathrm{~mm}$.

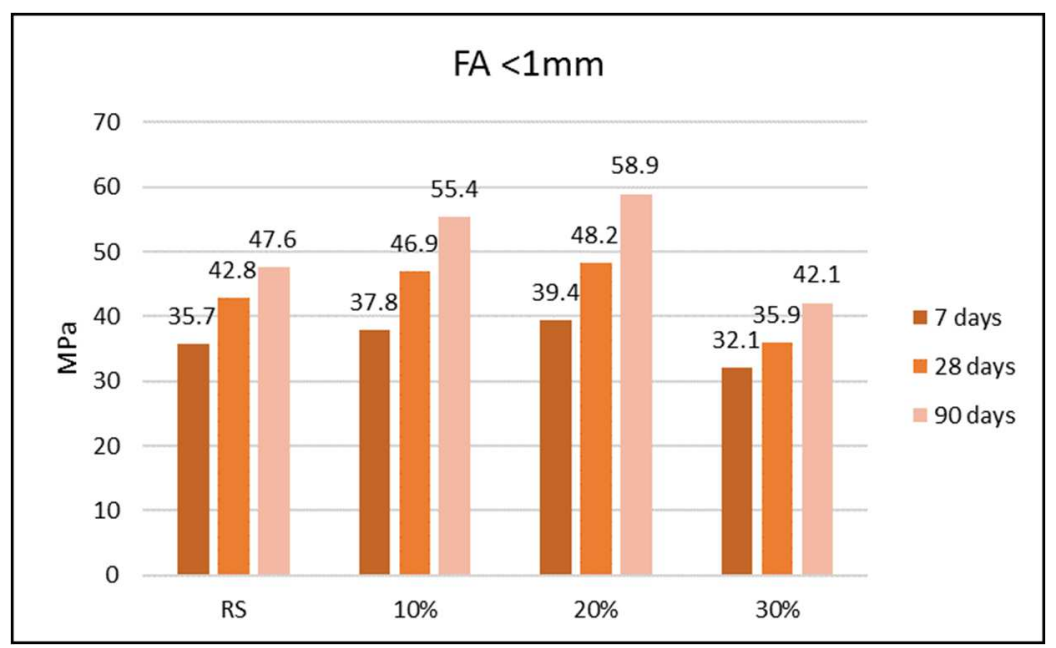

Figure 5. Compressive strength of GP based on FA with the addition of WG below $1 \mathrm{~mm}$.

Compressive strengths results are shown in Figures 4 (GGBFS) and 5 (FA). A similar trend occurred regarding strengths, which results in better strengths with geopolymers made of FA but GGBFS based geopolymers strengths were lower than the reference sample. Adding WG to the GGBFS mixture lowered the final strengths, although the amount of addition showed no significant difference; hence, all samples had quite similar results. FA based geopolymers with the addition of WG proved to be better than the reference sample made by only FA. The highest strengths were achieved on the $90^{\text {th }}$ day in all samples, and strengths were rising over time. Sample with $20 \%$ addition had the highest strength of $58.9 \mathrm{MPa} .20 \%$ addition of WG shows that this is the limit for addition to FA based geopolymers, as a higher percentage of addition lowers final compressive strengths in the sample.

Water absorption was examined over 24 hours (1440 minutes) after 10, 40, 90, 360, and 1440 minutes of sample immersion. The measured values of water absorption in prepared geopolymers are shown in Figures 6 (GGBFS) and 7 (FA). Results show that the addition of WG has an unfavorable effect on GGBFS based geopolymers. More of the WG addition means higher water absorption due to the more porosity of materials. The reference sample in this case with $8.4 \%$ of water absorbed was the best result. FA based geopolymers, on the other hand, as was expected from strengths results, show that the addition of WG glass has a positive effect on water absorption tests, where $10 \%$ addition and $20 \%$ addition of WG led to lower values of water absorption of samples. After 24 hours, the sample with $20 \%$ WG absorbed $8.1 \%$ water. 


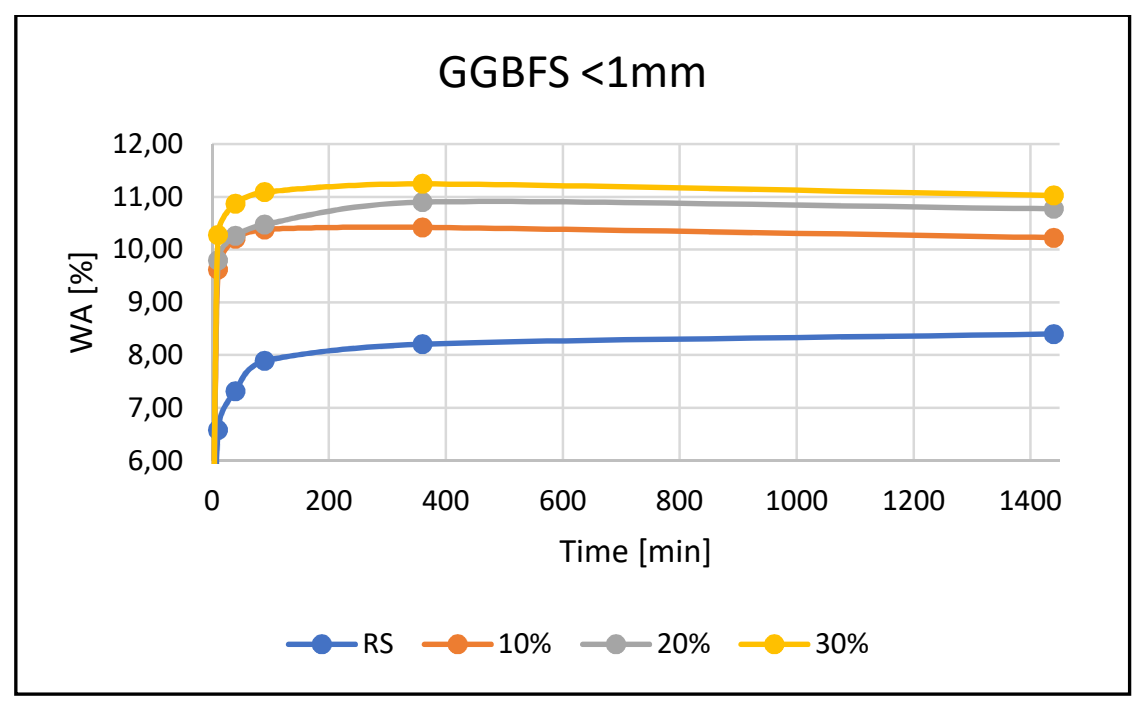

Figure 6. Water absorption of GGBFS geopolymers with WG addition below $1 \mathrm{~mm}$.

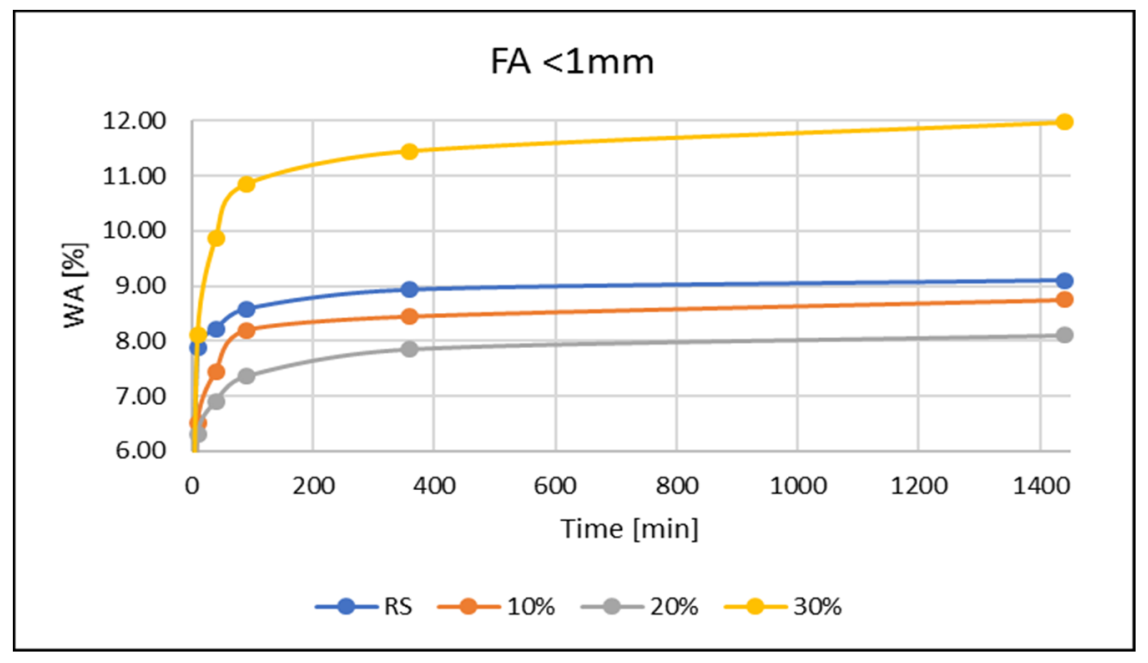

Figure 7. Water absorption of FA geopolymers with $W G$ addition below $1 \mathrm{~mm}$.

\section{Addition of waste glass fraction $>1 \mathrm{~mm}$}

The second set of experiments was performed with the same conditions as the first one. The only difference was that the WG particle size was bigger $(>1 \mathrm{~mm})$. Results of flexural and compressive strengths are in Figures 8 to 11 .

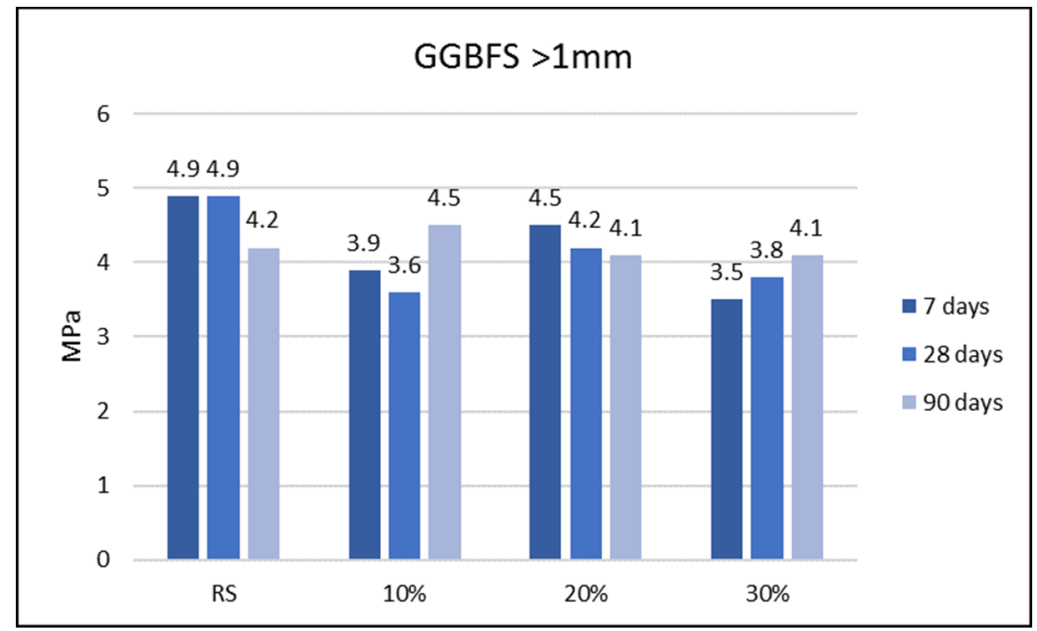

Figure 8. Flexural strength of GP based on GGBFS with the addition of WG over $1 \mathrm{~mm}$. 


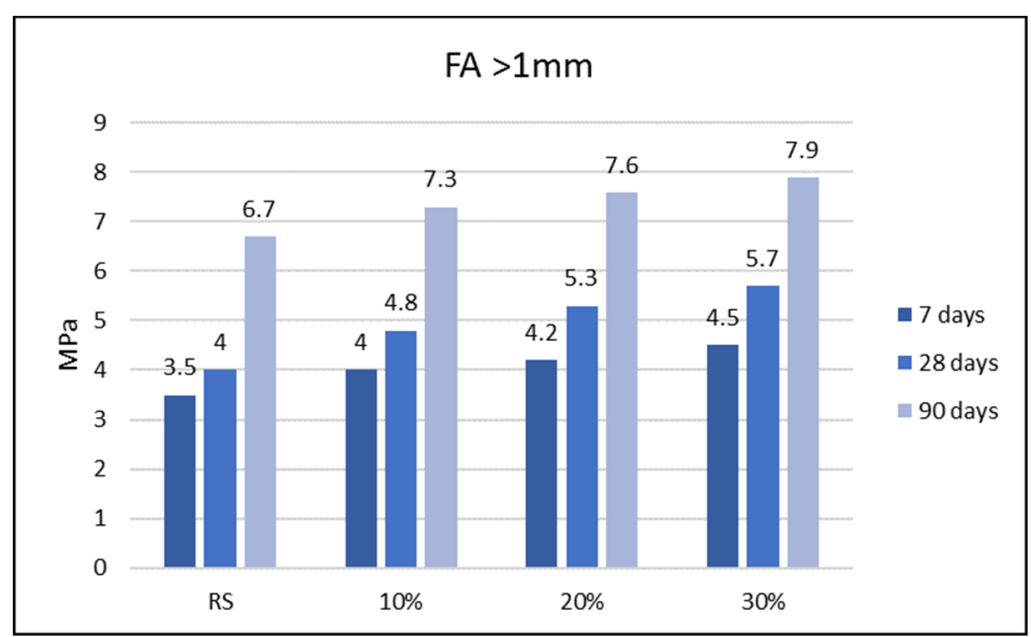

Figure 9. Flexural strength of GP based on FA with the addition of WG over $1 \mathrm{~mm}$.

The result of flexural strength shows that the samples did not only fail to increase flexural strengths, but the strengths also decreased over time. The reference sample yielded the highest strengths. On the contrary, results with FA were better compared to those with GGBFS. Flexural strengths were rising in time and achieved higher strengths than the reference sample. The highest strength $(7.9 \mathrm{MPa})$ was achieved for the sample with $30 \%$ addition after 90 days of hardening.

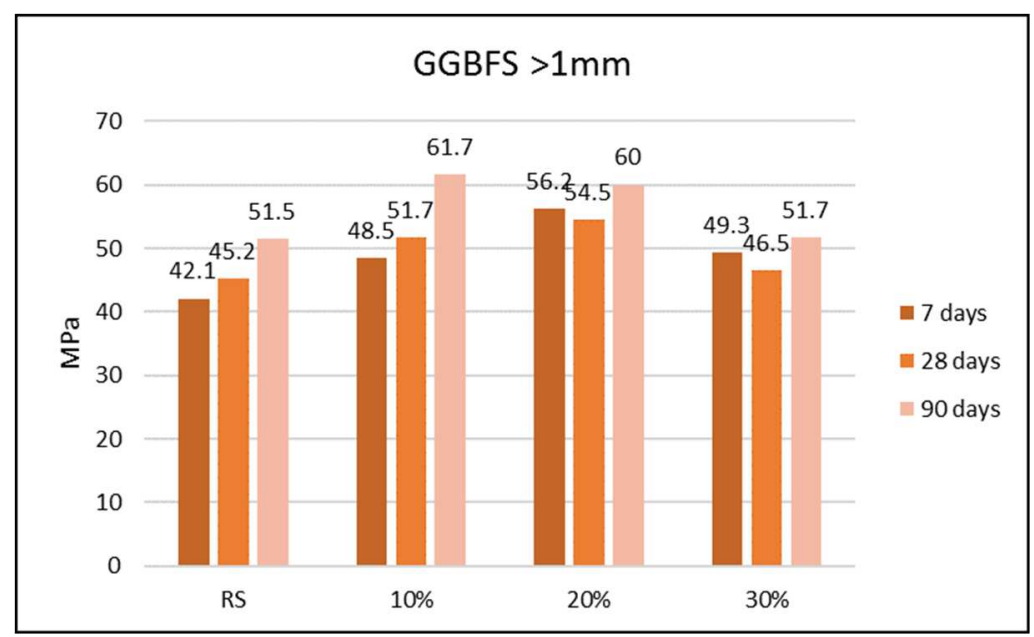

Figure 10. Compressive strength of GP based on GGBFS with the addition of WG over $1 \mathrm{~mm}$.

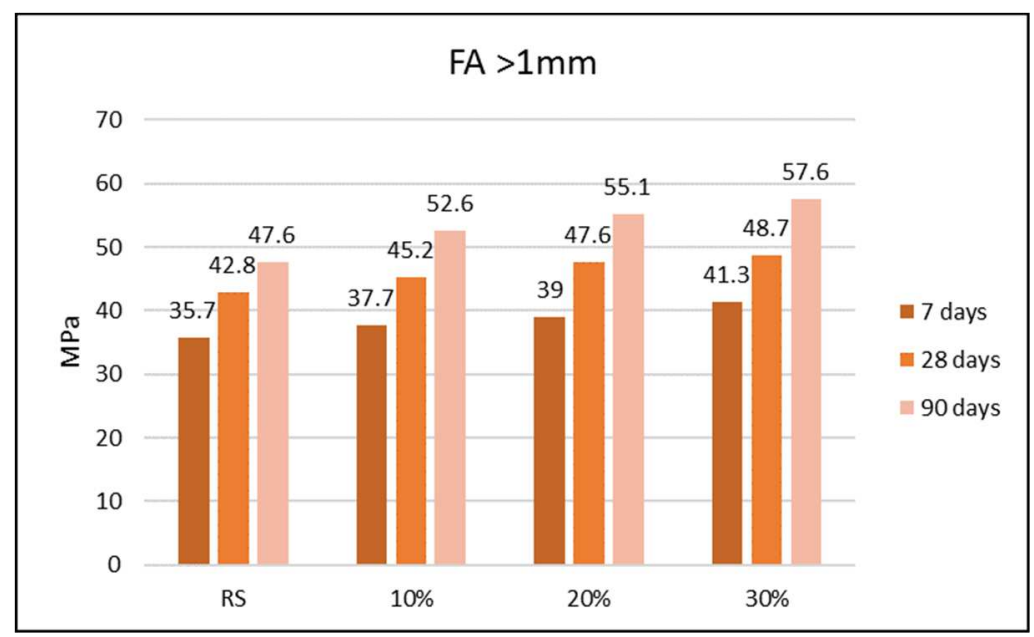

Figure 11. Compressive strength of GP based on FA with the addition of WG over $1 \mathrm{~mm}$. 
The compressive strength of WG with a particle size > $1 \mathrm{~mm}$ was improved. The hardened samples with $10 \%$ and $20 \%$ of the WG in the mixture showed slightly higher values of this strength parameter compared to the reference samples. The addition of $30 \% \mathrm{WG}$, on the other hand, resulted in a decrease in power. Samples with $10 \%$ addition and $20 \%$ addition of $>1 \mathrm{~mm}$ WG achieved the highest compressive strengths in all series of experiments. After 90 days, it was $61.7 \mathrm{MPa}(10 \%)$ respectively $60 \mathrm{MPa}(20 \%)$.

Samples created by FA and the addition of WG have a similar result to the reference sample. Only a small improvement was observed. Higher addition of WG resulted in higher compressive strengths. Highest achieved strength was for sample made by FA and 30\% addition of WG after 90 days, 57.6 MPa. It was the second-highest strength measured with FA, after $20 \%$ addition of $<1 \mathrm{~mm} \mathrm{WG}$ sample.

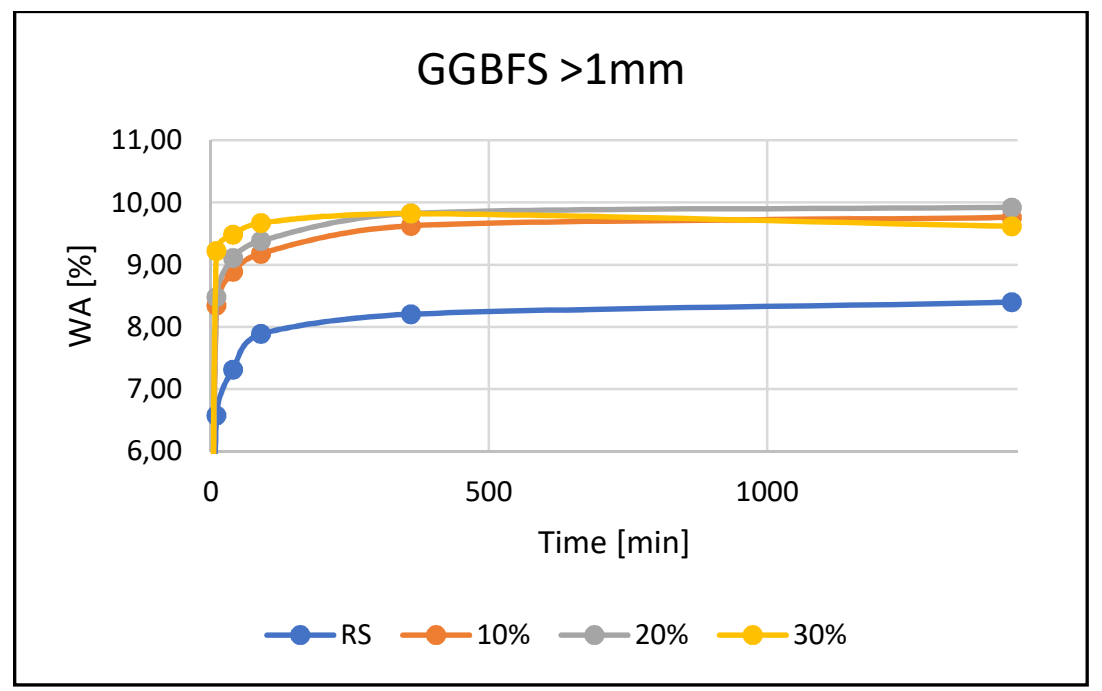

Figure 12. Water absorption of GGBFS geopolymers with WG addition over $1 \mathrm{~mm}$.

Water absorption tests are shown in Figures 12 and 13. The results show that adding WG to GGBFS based geopolymers has a negative impact. Water absorption values increased as more WG was added to the mixture; the same occurred with a smaller size of WG. The best result, in this case, was the reference sample, which absorbed $8.4 \%$ of the water. FA based geopolymers, on the other hand, show that the addition of WG glass has a positive impact on water absorption tests, with $10 \%$ and $20 \%$ additions of WG lowering the water absorption of samples, as predicted from strength findings. These results copied the results with smaller WG. After 24 hours, the sample with $20 \%$ WG absorbed $7.8 \%$ of water. We can conclude that size of WG has no affection to water absorption of geopolymers, only the amount of WG.

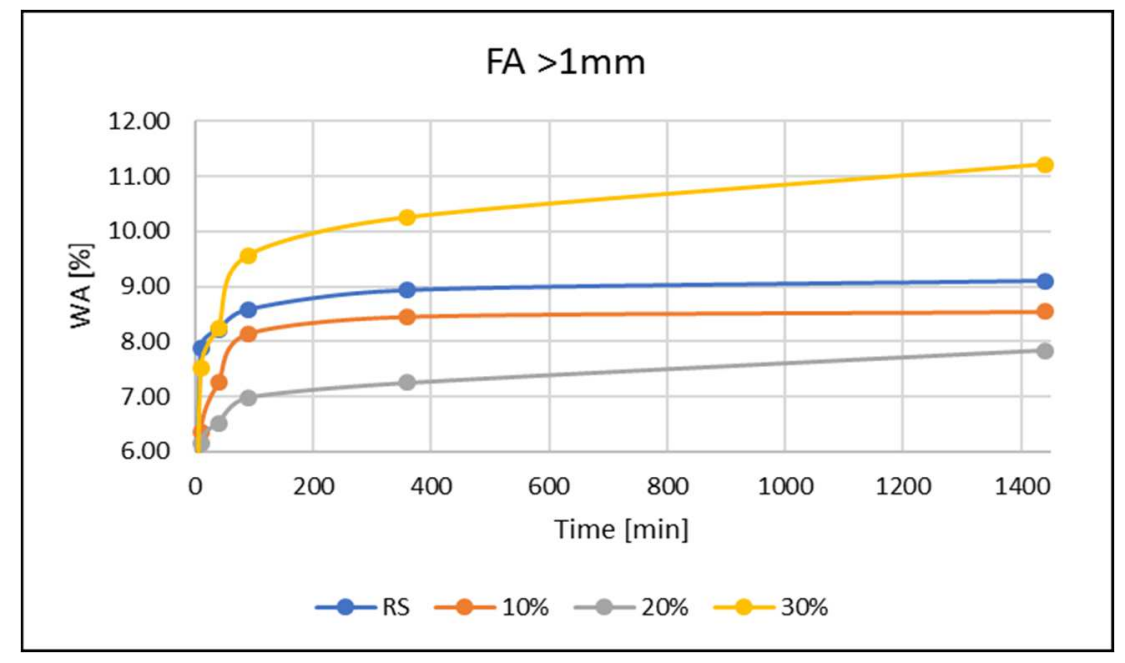

Figure 13. Water absorption of FA geopolymers with WG addition over $1 \mathrm{~mm}$.

In comparison with other works (Luhar et al., 2019; Bai et al., 2019), our geopolymers samples have achieved higher strengths after 28 days. Luhar et al. (2019) and Bai et al. (2019) prepared samples by using foam waste 
glass, which is different from our procedure of creating GP. Therefore, coarser WG particles may better help the process of geopolymerization.

The application of WG is quite practical in industrial geopolymers as a raw material in forms like a wasteglass powder, glass cullet, fine sand, soda-lime glass, etc., and as a precursor for alkaline binders in geopolymer production.

FA geopolymers showed generally higher strengths than GGBFS geopolymers, due to the smaller particle size of FA. Smaller particle size always contributed to a higher degree of geopolymerization and better compressive and flexural strengths. FA particles encapsulated the WG particles better than GGBFS.

\section{Conclusions}

For many purposes, there is an increasing demand for new materials that have low $\mathrm{CO}_{2}$ emissions connected with their production. Alkali activated materials - geopolymers, are a new generation of inorganic binders. Any aluminosilicate materials can be used to prepare geopolymers, including fly ash and slag. So, geopolymer concrete could be utilized potentially as a replacement for OPC. However, this will only occur when both an efficient supply chain for raw materials and a supply network for the products are in place

A laboratory investigation was performed to study the effects of WG addition and its influence on mechanical properties such as compressive and flexural strengths of geopolymers. WG from waste bottles, fly ash, and ground granulated blast furnace slag were utilized for the creation of geopolymer samples. Three types of WG addition were used $(10,20$, and $30 \%$ by weight).

The results show that WG does not always improve the mechanical strengths of the produced material (GGBFS). In the case of FA, there is a slight potential of WG addition, which can be beneficial for further investigation.

In the case of water absorption, WG with GGBFS has higher water absorption. Increasing the amount of WG water absorption was increasing. Conversely, WG helped FA samples to lower the water absorption, which is due to the smaller particle size of FA samples.

\section{References}

Arai, Y., Powell, B. A., \& Kaplan, D. I. (2017). Sulfur speciation in untreated and alkali treated ground granulated blast furnace slag. Science of The Total Environment, 589, 117-121. https://doi.org/10.1016/j.scitotenv.2017.02.163

Bai, C., Li, H., Bernardo, E., \& Colombo, P. (2019). Waste-to-resource preparation of glass-containing foams from geopolymers. Ceramics https://doi.org/10.1016/j.ceramint.2018.12.227

Buchwald, A., Zellmann, H. D., \& Kaps, C. (2011). Condensation of aluminosilicate gels-model system for geopolymer binders. Journal of Non-Crystalline Solids, 357(5), 1376-1382. https://doi.org/10.1016/j.jnoncrysol.2010.12.036

Cilla, M. S., Colombo, P., \& Morelli, M. R. (2014). Geopolymer foams by gelcasting. Ceramics International, 40(4), 5723-5730. https://doi.org/10.1016/j.ceramint.2013.11.011

Davidovits, J. (2017). Geopolymers: Ceramic-like inorganic polymers. Journal of Ceramic Science and Technology, 8(3), 335-350. DOI: 10.4416/JCST2017-00038

Dindi, A., Quang, D. V., Vega, L. F., Nashef, E., \& Abu-Zahra, M. R. (2019). Applications of fly ash for $\mathrm{CO}_{2}$ capture, utilization, and storage. Journal of $\mathrm{CO}_{2}$ Utilization, 29, 82-102. https://doi.org/10.1016/j.jcou.2018.11.011

Giergiczny, Z. (2019). Fly ash and slag. Cement and Concrete Research, 124, 105826. https://doi.org/10.1016/j.cemconres.2019.105826

Kanuchova, M., Drabova, M., Sisol, M., Mosej, J., Kozakova, L., \& Skvarla, J. (2016). Influence of mechanical activation of fly ash on the properties of geopolymers investigated by XPS method. Environmental Progress \& Sustainable Energy, 35(5), 1338-1343. https://doi.org/10.1002/ep.12353

Luhar, S., Cheng, T. W., Nicolaides, D., Luhar, I., Panias, D., \& Sakkas, K. (2019). Valorisation of glass waste for development of Geopolymer composites-Mechanical properties and rheological characteristics: A $\begin{array}{llll}\text { review. Construction } \text { and } & \text { Building }\end{array}$ https://doi.org/10.1016/j.conbuildmat.2019.06.041

Michalíková, F., Škvarla, J., Sisol, M., Krinická, I., \& Kolesárová, M. (2010). Treatment processes for utilization of high carbon fly ashes from combustion of black coal in thermal power plants. Inżynieria Mineralna. Vol, 11, 9-26. Available at: http://www.potopk.com.pl/Full text/2010_full/2010_1_02.pdf

Sisol, M., Kolesarova, M., Krinicka, I., Michalikova, F., \& Mária, P. (2010). The evaluation of geopolymer properties prepared by alkali activation of black coal ashes with high content of loss on ignition. Acta 

Montanistica
Slovaca, 15(4),
277.
Available
at:

https://citeseerx.ist.psu.edu/viewdoc/download?doi=10.1.1.221.2812\&rep=rep1\&type=pdf

Sisol, M., Drabová, M., \& Mosej, J. (2014). Alkali activation of fresh and deposited black coal fly ash with high loss on ignition. Gospodarka Surowcami Mineralnymi-Mineral Resources Management. 30(2), 1-13. https://doi.org/10.2478/gospo-2014-0014

Snellings, R., Mertens, G., \& Elsen, J. (2012). Supplementary cementitious materials. Reviews in Mineralogy and Geochemistry, 74(1), 211-278. https://doi.org/10.2138/rmg.2012.74.6

Škvarla, J., Sisol, M., Botula, J., Kolesarova, M., \& Krinicka, I. (2011). The potential use of fly ash with a high content of unburned carbon in geopolymers. Acta Geodynamica et Geomaterialia, 8(2):123 - 132. Available at: https://dspace5-test.vsb.cz/bitstream/handle/10084/89105/acta-geodyn-geomater-2011-8-2123-skvarla.pdf?sequence $=2$

Škvára, F. (2007). Alkali activated materials or geopolymers. Ceramics-Silikáty, 51(3), 173-177. Avaible at: http://www.geopolymery.eu/aitom/upload/documents/publikace/2007/2007_03 173.pdf

Toniolo, N., \& Boccaccini, A. R. (2017). Fly ash-based geopolymers containing added silicate waste. A review. Ceramics International, 43(17), 14545-14551. https://doi.org/10.1016/j.ceramint.2017.07.221

Wang, H., Ding, B., Liu, X. Y., Zhu, X., He, X. Y., \& Liao, Q. (2017). Solidification behaviors of a molten blast furnace slag droplet cooled by air. Applied Thermal Engineering, 127, 915-924. https://doi.org/10.1016/j.applthermaleng.2017.07.215

Wang, S., Zhang, C., \& Chen, J. (2014). Utilization of coal fly ash for the production of glass-ceramics with unique performances: a brief review. Journal of Materials Science \& Technology,30(12), 1208-1212. https://doi.org/10.1016/j.jmst.2014.10.005

Wu, Y. G., Xie, S. S., Zhang, Y. F., Du, F. P., \& Cheng, C. (2018). Superhigh strength of geopolymer with the addition of polyphosphate. Ceramics 2578-2583. https://doi.org/10.1016/j.ceramint.2017.11.020

Wu, Y., Lu, B., Bai, T., Wang, H., Du, F., Zhang, Y., ... \& Wang, W. (2019). Geopolymer, green alkali activated cementitious material: Synthesis, applications and challenges. Construction and Building Materials, 224, 930-949. https://doi.org/10.1016/j.conbuildmat.2019.07.112

Xu, H., \& Van Deventer, J. S. J. (2000). The geopolymerisation of alumino-silicate minerals. INTERNATIONAL JOURNAL OF MINERAL PROCESSING, 59(3), 247-266. https://doi.org/10.1016/S0301-7516(99)00074-5 